\title{
Balanced Scorecard: adequação para a gestão estratégica nas organizações públicas
}

Rozelito Felix, Patrícia do Prado Felix e

Rafael Timóteo

\section{Introdução}

O valor tangível de uma empresa do setor privado está refletido nos seus controles financeiros, representado pelo seu balanço. No entanto, para o setor público, o valor de um órgão se reflete na maneira como seus "clientes" usam os serviços que são oferecidos para os diversos segmentos da sociedade. Por exemplo: Sabemos qual é o valor de um órgão que presta serviços educacionais, de saúde, de transporte, de segurança? Qual é a importância desses serviços para o cidadão/sociedade? Ao mesmo tempo, também é necessário saber: como os recursos previstos no orçamento destinado a cada órgão estão sendo gastos e controlados? Como os investimentos estão sendo realizados? Existe a real necessidade de conhecer indicadores que possam subsidiar a tomada de decisões nessas questões.

O acompanhamento dos resultados, o alcance das metas e o maior controle da qualidade da prestação dos serviços públicos, que são oferecidos ao cidadão/ sociedade, são princípios que foram inseridos na Emenda Constitucional 19/98. 
Outro princípio bastante interessante e que irá proporcionar maior controle orçamentário, organização e transparência está previsto na Lei Complementar 101/ 2000 - Lei de Responsabilidade Fiscal.

A implementação de um modelo de gestão estratégica se faz necessária e merece especial atenção em sua aplicação. Os órgãos da APF e o cidadão/ sociedade necessitam de serviços que os auxiliem na prevenção de suas ações e na continuidade de suas operações.

Diante de tal necessidade identificouse que o modelo de Balanced Scorecard, desenvolvido por Kaplan e Norton, seria o exemplo a ser implementado, dentro de um contexto de adaptações, pois é amplamente utilizado no mercado nacional e internacional; inclusive sendo usado pelo TCU, como descreve o Acórdão 1952/2007:

3.1 - Indicadores de Gestão: O Anexo II da DN/TCU no 81/2006 contém três itens (02, 03 e 04 da Seção 1) que tratam de formas diferentes $O$ mesmo tema, qual seja, indicadores de desempenho da gestão. A IN/TCU $n^{\circ} 47 / 2004$ já havia avançado consideravelmente ao considerar o controle do desempenho da gestão, como forma de contribuição para o aperfeiçoamento da Administração Pública, como princípio a ser considerado no exame e julgamento das tomadas e prestações de contas dos gestores.

O BSC mantém o equilíbrio nas dimensões orçamentárias e não orçamentárias do negócio, permitindo ao nível estratégico monitorar os órgãos da APF com a visão operacional de longo prazo.

Pode-se citar alguns órgãos púbicos que já utilizam o BSC como modelo de gestão estratégica: Gabinete de Segurança Institucional da Presidência da República (GSI/PR), por intermédio do Departamento de Segurança da Informação e Comunicações (DSIC), Ministério da Agricultura, Pecuária e Abastecimento (MAPA), Ministério Público do Estado de Goiás, Prefeitura de Curitiba, Banco Nacional de Desenvolvimento Econômico e Social (BNDES), Governo do Estado de Minas Gerais, Governo do Rio de Janeiro.

Destaca-se o Conselho Nacional de Justiça (CNJ) que, em 2010, reuniu os presidentes dos tribunais e demais órgãos do Poder Judiciário brasileiro no III Encontro Nacional do Judiciário e, em conjunto, elaboraram o mapa estratégico com 10 metas prioritárias para que os demais órgãos do Judiciário promovessem encontros regionais e definissem suas estratégias com base no mapa instituído. Com isto estabeleceu-se um grande painel de medição de desempenho do Judiciário.

Pensando nesse desafio, adaptou-se uma arquitetura para gestão e tradução das estratégias em um conjunto organizado de informações que são agrupadas em perspectivas: cidadão/sociedade, Administração Pública Federal (APF), processos internos, relações governamentais, aprendizado e crescimento orçamentário. Esse modelo adaptado é o Balanced Scorecard.Gov (BSC.Gov).

\section{Gestão estratégica}

A estratégia tem um caráter revolucionário, declara Henderson (1998).

Estratégia é a busca deliberada de um plano de ação para desenvolver e ajustar a vantagem competitiva de uma empresa. Para qualquer empresa, a busca é um processo interativo que 
começa com o reconhecimento de quem somos e do que temos nesse momento. Seus competidores mais perigosos são os que mais se parecem com você. As diferenças entre você e seus competidores são a base da sua vantagem (HENDERSON, 1998).

A palavra estratégia significa "a arte da liderança". Inserir estratégia no contexto da organização significa: a) descrever como alcançar as metas e objetivos organizacionais; b) considerar os valores pessoais e sociais existentes na empresa; c) orientar a utilização de pessoas e de recursos financeiros; d) criar e sustentar vantagem competitiva (Tiffany e Peterson, 1998).

Tiffany e Peterson (1998) associam normalmente a falha de estratégia a aspectos não relevantes, considerados como essenciais, e o sucesso da estratégia à garantia de um processo de adequação do planejamento com as operações contínuas do negócio.

A estratégia é uma forma de fazer bons negócios a longo prazo. Trata-se de processo contínuo que necessita de indicadores efetivos. Precisa estar de acordo com a situação em que se encontra a organização, visando a sobrevivência, a manutenção, o crescimento ou o desenvolvimento. $\mathrm{O}$ sucesso de uma estratégia se vincula "a fazer as perguntas certas e a encontrar boas respostas". Uma estratégia é competitiva quando busca posição favorável ao nicho de mercado, visando se estabelecer em posição lucrativa e sustentável (Tiffany e Peterson, 1998; Oliveira, 1999; Porter, 1989).

Segundo Oliveira (1999), a estratégia é um caminho que visa o alcance, de forma diferenciada, de objetivos estabelecidos. A estratégia não é o único fator a determinar o fracasso ou o sucesso da organização, seu corpo administrativo tem equivalência de importância idêntica ao da estratégia.

O planejamento estratégico é o primeiro item a ser abordado pela administração estratégica, pois possibilita o planejamento do desenvolvimento e de mudanças organizacionais. Nesse processo a empresa é considerada de forma completa, mas pressupõe que o todo também possa ser representado por uma unidade de negócio. Tal planejamento pode ser abordado em

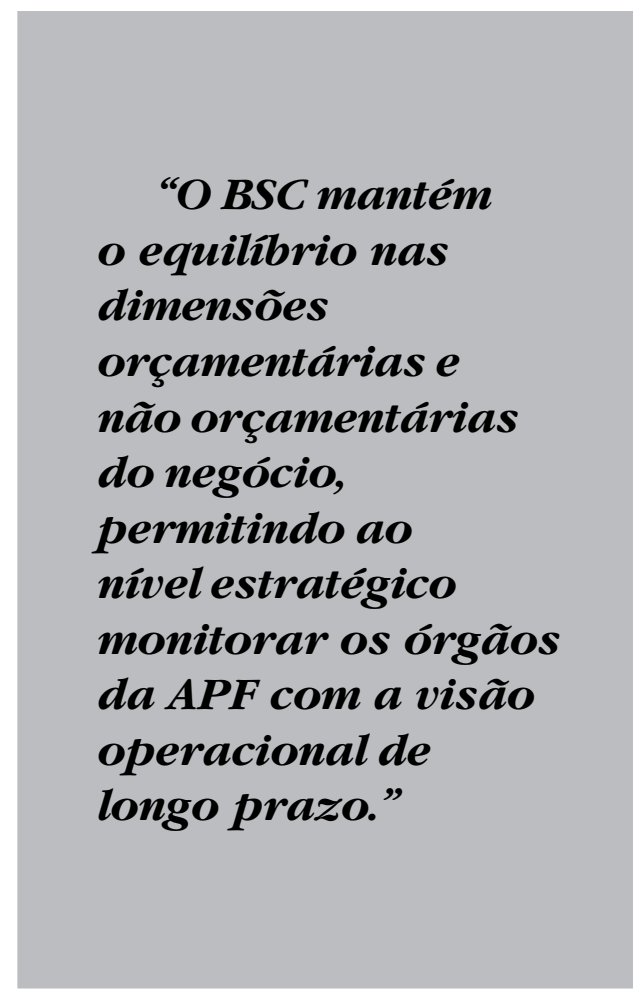

três níveis: estratégico, tático e operacional. No nível estratégico, permite estabelecer a direção a ser seguida pela organização; no tático, tem a finalidade de otimizar uma unidade de negócio da organização; e no operacional, são definidas formas de desenvolvimento e de implementação de resultados específicos a serem alcançados (Certo, 1993; Oliveira, 1999). 
O processo de planejamento estratégico tem o propósito de aumentar a eficácia de uma organização ou de uma unidade de negócio e aprimorar sua missão, sendo considerado uma forma sustentável para a criação de valores organizacionais (Kaplan e Norton, 2000).

Segundo Certo (1993), o processo de administração estratégica é dividido em cinco etapas básicas: execução de análise do ambiente, estabelecimento de diretriz organizacional, formulação de estratégia organizacional, implementação da estratégia organizacional e exercício do controle estratégico.

A análise do ambiente tem o propósito de identificar riscos e oportunidades, que influenciam na realização das metas organizacionais. Estabelecer a diretriz da organização trata-se essencialmente da definição da missão e dos objetivos organizacionais.

A formulação de uma estratégia organizacional visa determinar ações apropriadas ao alcance dos objetivos. Trata-se dos três níveis estratégicos presentes nas organizações: organizacional, de negócio e funcional. A implementação de estratégia compreende a colocação da estratégia em ação. $\mathrm{O}$ controle estratégico consiste em fazer com que o planejado se desenvolva. Abrange como comparar o desempenho organizacional real com as metas e padrões estabelecidos.

Segundo Kaplan e Norton (2000), a implementação de uma estratégia nunca foi tão necessária como atualmente no ambiente organizacional. No entanto, a grande maioria das organizações que consegue constituir a sua estratégia, não tem êxito em sua execução, ocasionando perda de força, uma vez que a implementação da estratégia se caracteriza por ser mais importante que sua própria qualidade.
No ambiente organizacional o que determina as principais intenções da empresa, o seu curso e o tempo para concretização da estratégia, são as metas e os objetivos. As metas são compromissos que a organização assume e os objetivos são especificações de como se pretende alcançar cada meta (OliveirA, 1999). Os objetivos estratégicos organizacionais fundamentam o planejamento, a organização, a motivação e o controle. Na falta deles, as organizações podem seguir quaisquer direções (CERTO, 1993).

O alinhamento e o foco são os termos que possibilitam atingir bons resultados estratégicos, a partir da sinergia entre as partes que compõem a organização. (Kaplan e Norton, 2000).

O alinhamento dos objetivos organizacionais garante a cada segmento significativo da organização, tais como divisões e departamentos, saber executar o seu papel de forma a possibilitar que os objetivos globais sejam alcançados. A definição dos subobjetivos deve permitir a realização dos objetivos organizacionais. A hierarquia dos objetivos pode atingir o nível individual ao estabelecer metas para cada um dos indivíduos que trabalhem na organização, de modo que cada um colabore na realização do objetivo do setor onde está lotado (GRANDER, 1963). Os bens intangíveis redirecionam a gestão dos tangíveis para a gestão de estratégias baseadas no conhecimento. A estratégia baseada no conhecimento se caracteriza pela relação com clientes, inovações de produtos e serviços, tecnologia da informação e banco de dados, além de considerar também as competências individuais dos empregados e ser capaz de alinhar unidades de negócio, unidades de apoio e funcionários à estratégia organizacional (KAPlan e Norton, 2000). 
A empresa que opta por uma política de valorização dos intangíveis precisa de indicadores que possam medir resultados no fim de um período, pois, de acordo com Kaplan e Norton (1997), o que não é medido, não pode ser gerenciado.

Segundo Herzog (2003), atualmente algumas empresas vêm realizando o chamado alinhamento da organização à estratégia de Kaplan e Norton (2000), a partir da elaboração do Balanced Scorecard corporativo e seu detalhamento nas áreas de negócios.

As organizações que têm o foco na estratégia exigem que seus funcionários conduzam atividades cotidianas de forma a agregar continuamente valores para seu êxito. A estratégia para ser efetiva não se caracteriza como um processo isolado, mas em contínua evolução (KAPLAN, 2000). Segundo Porter (1990), a construção de uma estratégia depende da atividade selecionada para se atingir a excelência. A diferença entre tipos de estratégia é a escolha dessas atividades e da forma pela qual serão executadas.

A avaliação da estratégia precisa acontecer não só após sua implementação, mas também no momento da sua escolha. A estratégia deve estar em concordância com a cultura, o clima organizacional e em sintonia com os aspectos externos à empresa (Oliveira, 1999).

A implementação de uma estratégia requer alinhamento corporativo, como processo contínuo e participativo (Figura 1).

A estratégia é alinhada à unidade de negócio, provocando o seu compartilhamento nas unidades de apoio e entre os indivíduos intra e inter unidade. Este processo propicia uma sinergia entre as unidades de negócios e os serviços da organização. A transformação dos ativos intangíveis envolve três categorias principais: as competências estratégicas, as tecnologias estratégicas e o clima favorável à ação (Figura 2) (KAPlan e Norton, 1997).

As competências estratégicas abordam habilidades e conhecimentos necessários ao reforço da estratégia, suportado por tecnologias que visam facilitar maior alcance dasmetas. Para que tudo isso seja viabilizado há necessidade de um clima apropriado às mudanças culturais necessárias à motivação, à capacitação e ao alinhamento com a estratégia (KAPLAN e Norton, 1997).

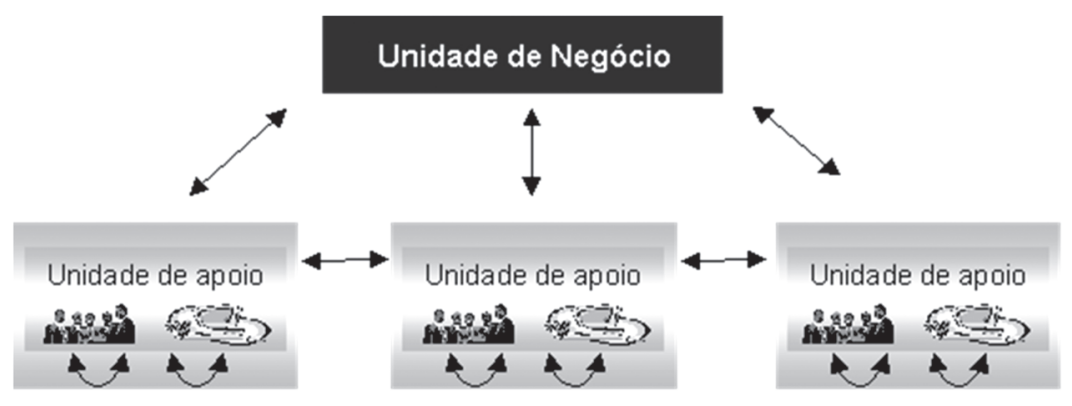

Fonte: adaptado de Kaplan (2000).

Figura 1: Sinergia das unidades organizacionais 


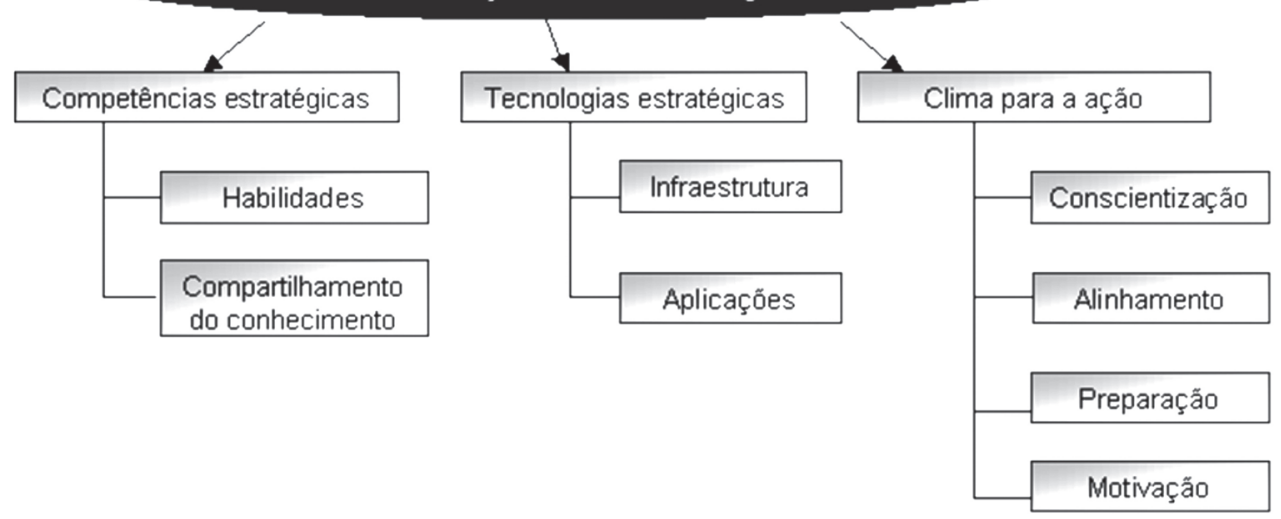

Fonte: adaptado de Kaplan e Norton (1997, p.138).

Figura 2: Transformação dos ativos intangíveis

\section{Balanced Scorecard}

\section{Conceitos}

O BSC foi desenvolvido pelos professores da Harvard Business School, Robert Kaplan e David Norton, em 1992, e envolve três grupos de ações: estratégicas, operacionais e organizacionais. O objetivo é o de estabelecer um processo estruturado para a criação de medidas financeiras e não financeiras, representadas por objetivos estratégicos e metas em todos os níveis, possibilitando a integração entre esses grupos e proporcionando o alinhamento de toda a organização.

O fato inédito no BSC é a inovação de medidores de desempenho futuro, focados estrategicamente em quatro perspectivas - financeira, clientes, processos internos e aprendizado e crescimento -, dentro de uma estrutura e linguagem que comunica visão e estratégia. A definição e integração dos objetivos estratégicos, das iniciativas, metas e indicadores dessas perspectivas constituem os pilares do BSC, que devem ser conectados ao pensamento estratégico da organização (Figura 3).
O Balanced Scorecard nasceu do estudo de métodos de mensuração, intitulado Measuring Performance in the Organization of the Future, de Robert Kaplan e David Norton, e se baseia em indicadores de ativos tangíveis (GiunTini, 2003).

Vários estudos de casos sobre sistemas de mensuração de desempenho foram analisados e, entre eles, o Analog Devices, que visa a mensuração do progresso em atividades de melhoria contínua. O Analog utilizava um scorecard corporativo, empregando medidas financeiras, relativas a prazos de entrega ao cliente, à qualidade e ciclo de processos de produção e ao desenvolvimento de novos produtos (Giuntin, 2003).

Diversas reuniões se realizaram com o objetivo de discutir o Analog e diversas ideias foram agregadas ao sistema original. A ampliação do método originou novo título "Balanced Scorecard" (Giuntini, 2003).

O Balanced Scorecard ${ }^{1}$ é um sistema que controla desde a identificação das necessidades até a motivação das melhorias dos processos e produtos, criando um ambiente propício ao alinhamento 


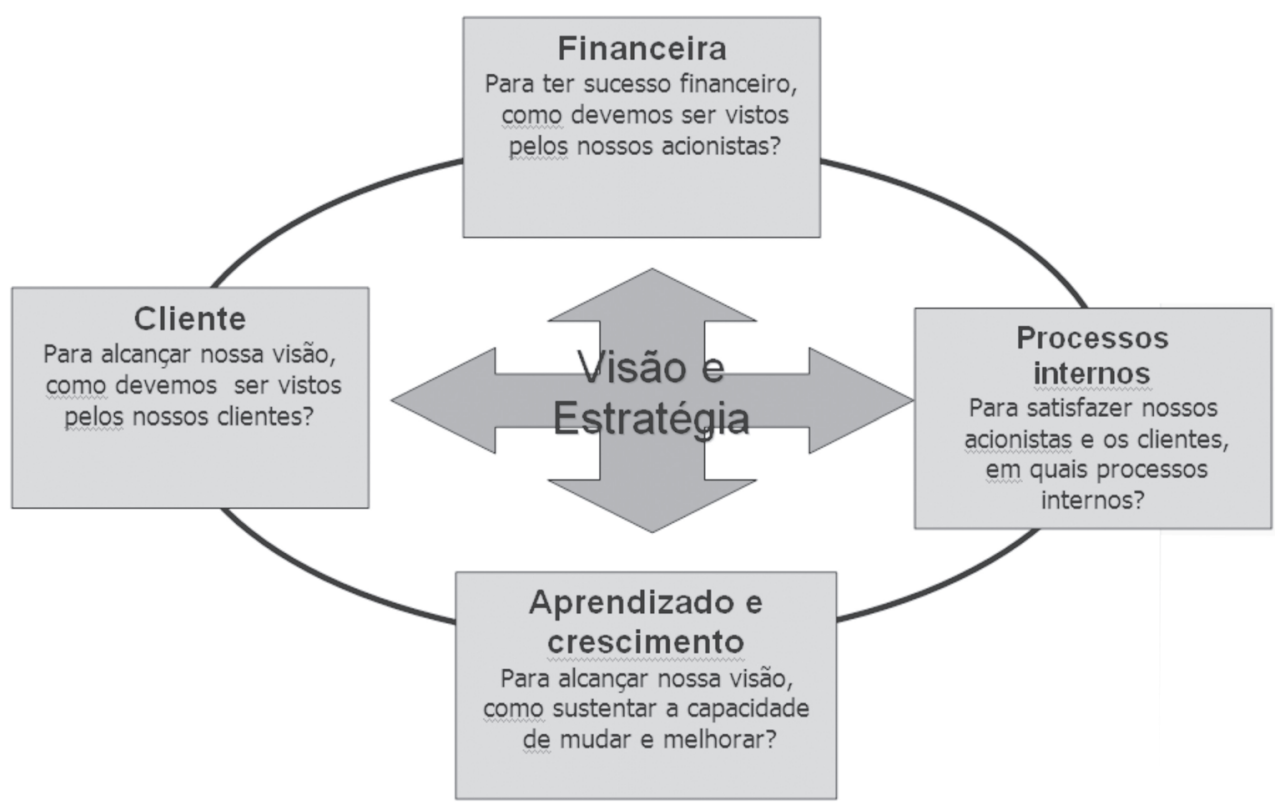

Fonte : Kaplan e Norton (2000).

\section{Figura 3: Visão geral das perspectivas do BSC}

estratégico organizacional. O BSC é responsável por traduzir os objetivos estratégicos em indicadores de desempenho classificados nas quatro perspectivas de Kaplan e Norton (1992): financeira, cliente, processos internos e aprendizado e crescimento.

Para Campos (1998), entender a denominação do Balanced Scorecard é relacionar a sua implementação com o equilíbrio dos quatro grupos de indicadores. O balanceamento é garantido pelo sucesso da estratégia nas quatro perspectivas.

Olve et al. (2001) baseiam-se no conceito do BSC apresentado por Kaplan e Norton (1992), que considera uma organização a partir de quatro perspectivas vitais, vinculando o controle operacional de curto prazo a uma visão estratégica de longo prazo do negócio. O controle operacional diário é considerado como impactante no resultado do desenvolvimento do amanhã, o que caracteriza três dimensões de tempo consideradas no Balanced Scorecard: passado, presente e futuro.

Ao mencionar Balanced Scorecard, Olve et al. (2001) referem-se ao grau de equilíbrio necessário entre os elementos da performance organizacional. O scorecard é um registro de resultados esperados e alcançados. Representa o plano de negócio das unidades da empresa e se torna um catalizador para as discussões a respeito dos rumos da organização.

Olve et al. (2001, p. 18) consideram as quatro perspectivas de Kaplan e Norton (1992, 1996), que se baseiam no seguinte modelo:

i) Para obtermos sucesso financeiro, como devemos encarar nossos acionistas?; ii) Para sermos bem-sucedidos nos nossos pontos de vista, como devemos encarar nossos clientes?; 
iii) Para satisfazermos nossos acionistas e clientes, em quais processos de negócio interno devemos nos sobressair?; iv) Para sermos bem-sucedidos em nossos pontos de vista, como devemos manter nossa capacidade de aprender e crescer?

Segundo Herzog (2003), nos últimos 15 anos destacaram-se poucos sistemas corporativos de gestão. O BSC é um instrumento de destaque na transformação de estratégias em realidade. Atualmente, algumas empresas vêm realizando o chamado "alinhamento da organização à estratégia" de Kaplan e Norton (2000), a partir da elaboração do BSC corporativo e de seu detalhamento em áreas de negócios.

Segundo Kaplan e Norton (2000), fator determinante de sucesso organizacional é a competência em maximizar os resultados de ativos intangíveis, porém existe uma dificuldade operacional de se medir esse procedimento. O Balanced Scorecard foi desenvolvido na década de 1990, com o objetivo de possibilitar o processo de mensuração. Entretanto, estudos comprovaram que sua utilização estava acontecendo para a implementação de novas estratégias, a partir da modelagem de alinhamento das unidades de negócios, de serviços e dos indivíduos às metas organizacionais. Em termos práticos, da visão, da estratégia e dos recursos, quando acionados adequadamente, fluem e refluem respostas viabilizadas como implementação, inovação, feedback e aprendizado.

As organizações focam suas estratégias com base no conhecimento e utilizam o BSC para operacionalizá-las, uma vez que a grande probabilidade de fracasso ou sucesso empresarial é a capacidade de execução da estratégia (KAPLAN e NorTON, 2000).
A estratégia formulada é possibilitada a partir da implementação do BSC nos diversos níveis organizacionais, de forma top-down, da unidade mais estratégica para a menos, podendo ser implementada como um piloto de navegação pela construção do BSC das unidades de negócios, posteriormente com o BSC das unidades de apoio e, finalmente, com o BSC Pessoal (Kaplan e Norton, 2000).

O BSC pessoal reforça os elos entre as áreas de negócios de forma a viabilizar a comunicação da estratégia e da educação da organização.

Segundo Kaplan e Norton (1997), o modelo financeiro tradicional, desenvolvido para empresas da era industrial, preocupa-se em medir tangíveis que participam de realizações do passado, enquanto as capacidades futuras de produção não são previstas. A orientação focada em elementos intangíveis não desconsidera a importância do foco financeiro.

A filosofia do scorecard, sintonizada com a nova economia do conhecimento e da informação, busca viabilizar a realização de quatro processos gerenciais complexos: esclarecimento na tradução da visão e da estratégia; comunicação e associação dos objetivos às medidas estratégicas; estabelecimento das metas e alinhamento das iniciativas estratégicas; e melhoramento do nível de feedback e do aprendizado estratégico (Kaplan e Norton, 1997).

O BSC é utilizado para alcançar o entendimento da missão e da estratégia de uma unidade de negócio, transformandoas em objetivos e medidas tangíveis. Há possibilidade de o BSC ser iniciado com objetivos restritos e posteriormente propagá-los por toda organização, deixando de ter a característica de um sistema de indicadores e passando a um sistema de gestão estratégica (KAPLAN e NORTON, 1997). 
A implementação do Balanced Scorecard contempla a necessidade de sistematizar uma ação estratégica, assegurando uma organização alinhada e focada na implementação da sua estratégia. O BSC é a integração de um sistema de mensuração com um sistema de gerenciamento que possibilita a implementação rápida e eficiente de estratégias (KAPLAN e NORTON, 1997 e 2002).

Como uma derivação do BSC, Kaplan e Norton criaram o Balance Scorecard Collaborative (BSCol), que possibilita novo tipo de serviço integrado que adiciona valor ao gerenciamento de processos. $\mathrm{O}$ BSCol está sendo usado por organizações responsáveis pelo processo de entrega de produtos e serviços.

A empresa que opta por uma política de valorização dos intangíveis, precisa de indicadores que possam medir resultados no fim de um período, pois, de acordo com Kaplan e Norton (1997), o que não é medido não pode ser gerenciado.

A perspectiva financeira está relacionada à liquidez e à lucratividade da empresa. Para a concretização do objetivo, consideram-se as medidas financeiras, como, por exemplo, o retorno do capital investido e fluxo de caixa, que são valiosas no acompanhamento do desempenho organizacional, indicando se a implementação da estratégia está contribuindo para a melhoria de seus resultados financeiros.

$\mathrm{Na}$ perspectiva do cliente, o BSC se propõe a identificar os segmentos de mercado afins com a unidade de negócios, e, posteriormente, identificar que indicadores de desempenho são relevantes apara a alavancagem do negócio. Nessa perspectiva ocorre o alinhamento das medidas diretamente vinculadas ao cliente, tais como: satisfação, fidelidade, retenção, captação e lucratividade, além de possibilitar, por meio da compreensão das necessidades dos clientes, maior competitividade no seu ramo de negócio.

A perspectiva dos processos internos da empresa tem foco na identificação dos pontos mais críticos e nos objetivos dos clientes e acionistas. Essa abordagem reflete uma estratégia completa, que possibilita aos processos existentes otimização e elaboração de novos, com a finalidade de atingir a excelência.

A última perspectiva do Balanced Scorecad pretende alcançar um constante aprendizado e crescimento organizacional. Compõe a base do BSC e impacta na perspectiva dos processos internos, na do cliente e na financeira.

Essa perspectiva provém basicamente de três fontes: o funcionário, os sistemas e o alinhamento estratégico organizacional. A fonte relacionada ao funcionário pode ser visualizada em três focos: satisfação, produtividade e retenção.

Entre as quatro perspectivas do BSC, essa é a que está menos desenvolvida, pois nela são agregadas a cobertura de funções estratégicas, a disponibilidade das informações estratégicas e o nível de alinhamento de pessoas, equipes e áreas com os objetivos estratégicos da organização. Os indicadores, que podem especificar tais desenvolvimentos, precisam ser personalizados considerando tais focos.

A perspectiva de aprendizado e crescimento, que trata da transformação dos ativos intangíveis, envolve três categorias principais: competências estratégicas, tecnologias estratégicas e clima favorável à ação.

A perspectiva do aprendizado e do conhecimento é como a raíz de uma árvore, a ela são atribuídos a sustentação, 
a nutrição e o crescimento. Considerando a estratégia organizacional, esse é o vetor mais efetivo no resultado, pois sustenta todas as outras perspectivas (Figura 4) (KAPlan e NorTon, 1997).

Segundo Santos (2003), o BSC é uma ferramenta de integração dos sistemas de gestão corporativa. O BSC converge os esforços estratégicos e visa o êxito da organização. O ambiente organizacional passa a se preocupar com o sucesso do todo, não mais com ações isoladas dos departamentos e dos funcionários. A criação do BSC objetivou focalizar não só o aspecto financeiro, mas todos os integrantes do processo de gestão. Em sua estrutura, o BSC desenvolve e alinha, nas quatro perspectivas, a visão empresarial e a sua estratégia.

Perspectivas financeiras, clientes, processos internos e de aprendizado e crescimento são desdobrados em objetivos estratégicos, indicadores, metas e planos de ação (SANTOS, 2003).

O BSC, na experiência de Boesen (2002), é a ferramenta utilizada para a gestão do desempenho organizacional. O BSC é responsável pela efetivação dos objetivos organizacionais, assim como pela descoberta de meios inovadores para alcançá-los. O referido autor menciona que o BSC permite estruturar as divisões da empresa que necessitam de melhorias, e que a aplicação de um BSC não ambicioso possibilitou o efetivo entendimento de seus gerentes.

Os sistemas de mensuração que se baseiam exclusivamente em números causam conflito na atual realidade econômica organizacional, que necessita de um desempenho métrico mais amplo; entretanto, as aplicações automatizadas de BSC não alinham as áreas funcionais às

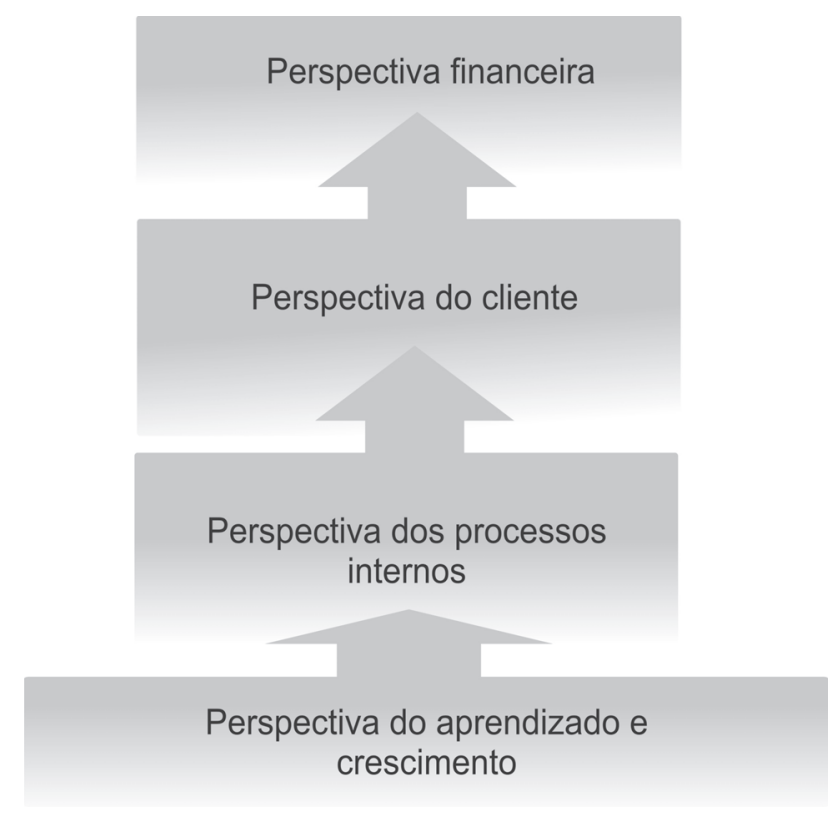

Fonte: Adaptado de Kaplan e Norton (1997) e de Averson (1999).

Figura 4: Relações de causa e efeito das perspectivas do Balanced Scorecard 
estratégicas. Os softwares ABM (Activitybased Management) e o EVA (Economic Value Added) possibilitam a mensuração de intangíveis, mas falta a eles um padrão que possibilite a comunicação entre aplicações diferentes que compõem o ambiente do negócio (Morris, 2002; Kaplan, 2002).

Considerando a complexidade e o potencial do BSC, a ferramenta é considerada efetiva para a gestão do conhecimento e auxilia no relato do "balanço social" da organização (Almeida, 1999).

De forma similar a Kaplan e Norton (1997), Giuntini (2003) considera que "o que não é medido, não é gerenciado". As organizações para manterem sua sustentação devem gerenciar seu desempenho com monitoramento por meio de medições. $\mathrm{O}$ Balanced Scorecard incorpora um conjunto integrado de medidas que analisa o desempenho sob a visão dos clientes, dos processos internos, dos funcionários e sistemas e do financeiro. A mensuração financeira é realizada a longo prazo e associada à finalização da síntese de desempenho organizacional.

As quatro perspectivas do BSC "devem ser entendidas como um modelo e não como camisa de força". São elas adequadas a uma variedade de empresas de diversos setores do mercado, mas não existe nenhum estudo que comprove que as quatro perspectivas sejam suficientes e definitivas (Giuntini, 2003, p. 9).

Uma organização que utiliza o BSC como ferramenta de gestão estratégica, possibilita ao gestor saber qual o impacto de sua decisão sobre a unidade de negócio e toda a estratégia organizacional. Auxilia também a visão das relações entre ações atuais e metas futuras (GIUNTINI, 2003).

Segundo Fresneda (2003), a implementação do BSC viabiliza a implantação de planos estratégicos, por possibilitar a eficiência das ações estratégicas, que garantem a condução da organização ao estadodesejado. O Balanced Scorecard possibilita a criação de modelo operacional e gerenciável de gestão estratégica, que pode ser adaptado por meio de estudos, avaliações, elaboração e implantação de um projeto piloto.

Norton (2002) associa o gerenciamento de estratégia com o gerenciamento da mudança, considerando que a necessidade de uma nova estratégia requer mudanças

“A implementação do Balanced Scorecard contempla a necessidade de sistematizar uma ação estratégica, assegurando uma organização alinbada e focada na implementação de sua estratégia."

organizacionais. Esse processo passa por três fases: mobilização, condução do projeto e execução sustentável. Em cada uma dessas fases o Balanced Scorecard pode ser utilizado com um objetivo distinto.

$\mathrm{Na}$ fase da mobilização o BSC é utilizado para esclarecer a estratégia; na fase de condução, é o instrumento que possibilita a explicação da nova estratégia da alta administração para todos os níveis da 
empresa; e na execução, o BSC educa e alinha as pessoas na organização, gerenciando as metas a serem efetivadas a longo prazo (NoRTON, 2002).

Para Becker et al. (2001), o BSC torna possível a mensuração do desempenho organizacional, sob a perspectiva da implementação da estratégia. A ferramenta apoia o desenvolvimento de formas tangíveis para avaliar os intangíveis. Os gerentes utilizam o BSC não apenas para monitorar os resultados. São agentes proativos na implementação da estratégia e garantem a expansão da estratégia em tarefa de todos.

Orientar o processo decisório e constituir o processo de avaliação de desempenho são objetivos do BSC, considerando-o um sistema de mensuração eficaz (BECKER et al., 2001).

Becker et al. (2001) acreditam que a utilização do Balanced Scorecard possa efetivar uma nova competência para a organização, o gerenciamento do desempenho estratégico. De acordo com os referidos autores, essa competência é criada a partir da união da implementação de uma estratégia da empresa com um sistema de mensuração de desempenho. A utilização do BSC garante aos gerentes a mensuração estratégica alcançada com a possibilidade de saber o que medir e como medir. O sucesso desse novo sistema está vinculado à ampla divulgação dos resultados do Scorecard a toda empresa.

\section{Perspectivas}

O BSC trabalha com objetivos estratégicos que se relacionam entre suas perspectivas (Quadro 1). Essas perspectivas, equilibradas com os objetivos de curto e longo prazo, são essenciais para a implementação da estratégia, desde que sejam integradas. Vejamos, a seguir, como ocorre o relacionamento.

\section{Balanced Scorecard - Limitações do BSC para a gestão estratégica no Governo Federal}

Embora o setor privado e o setor público tenham como foco a preocupação em satisfazer o "cliente", eles diferem quanto à amplitude de suas metas e ações, e ao perfil de seus clientes; bem como na forma como utilizam os seus recursos financeiros (Quadro 2). Todavia, a satisfação do cidadão é uma obrigação do Estado e os seus interesses são direcionados para a coletividade.

As perspectivas de processos internos e de aprendizado e crescimento atendem plenamente às atividades desenvolvidas pela APF; por outro lado, o BSC não apresenta uma perspectiva que contemple as ações que são desenvolvidas pelos diversos conselhos, câmaras, comitês e grupos de trabalho, dos quais fazem parte os servidores que pertencem aos órgãos da APF e que são designados para a participação nesses grupos. Tais participações geram ações que podem ocasionar impactos nos processos internos de cada órgão.

Diante dessas observações, são identificadas as limitações do modelo de BSC, desenvolvido por Kaplan e Norton, para atender aos órgãos da Administração Pública Federal.

\section{Balanced Scorecard.Gov}

\section{Adaptações no BSC para aplicação da gestão estratégica nas organizações públicas}

Mediante a análise realizada, identificou-se que o modelo tradicional de BSC não é totalmente adequado aos órgãos da APF, sendo necessárias adaptações, que giram em torno de agregação e adequação de perspectivas. 
Quadro 1: Relações entre as perspectivas do BSC

\begin{tabular}{|c|c|c|c|}
\hline $\begin{array}{l}\text { Perspectiva de } \\
\text { origem }\end{array}$ & Descrição & Indicadores & $\begin{array}{l}\text { Perspectiva de } \\
\text { relação }\end{array}$ \\
\hline Financeira & $\begin{array}{l}\text { Os objetivos financeiros giram } \\
\text { em torno do resultado final da } \\
\text { estratégia, satisfação dos acionistas, } \\
\text { crescimento ou custos. }\end{array}$ & $\begin{array}{l}\text { Faturamento } \\
\text { Retorno sobre opera- } \\
\text { ções de investimento } \\
\text { Valor econômico } \\
\text { agregado } \\
\text { Aumento de receitas } \\
\text { Redução de custos }\end{array}$ & Processos Internos \\
\hline Clientes & $\begin{array}{l}\text { Avalia o desempenho da institui- } \\
\text { ção na concepção do cliente. } \\
\text { Importância na identificação dos } \\
\text { clientes. }\end{array}$ & $\begin{array}{l}\text { Participações de } \\
\text { mercado } \\
\text { Aquisição de clientes } \\
\text { Retenção de clientes } \\
\text { Lucratividade dos } \\
\text { clientes } \\
\text { Nível de satisfação } \\
\text { dos clientes }\end{array}$ & $\begin{array}{l}\text { Processos Internos } \\
\text { Financeira }\end{array}$ \\
\hline $\begin{array}{l}\text { Processos } \\
\text { internos }\end{array}$ & $\begin{array}{l}\text { Aborda os processos críticos que } \\
\text { geram valor. } \\
\text { A qualidade dos processos e a } \\
\text { tomada de decisões estão direta- } \\
\text { mente relacionadas com as causas } \\
\text { de insatisfação ou melhorias das } \\
\text { necessidades dos clientes. }\end{array}$ & $\begin{array}{l}\text { Tempo e qualidade } \\
\text { dos processos } \\
\text { internos } \\
\text { Excelência de proces- } \\
\text { sos críticos }\end{array}$ & $\begin{array}{l}\text { Clientes } \\
\text { Financeira }\end{array}$ \\
\hline $\begin{array}{l}\text { Aprendizado e } \\
\text { crescimento }\end{array}$ & $\begin{array}{l}\text { Desenvolve a capacidade de melho- } \\
\text { rar, inovar, aprender e crescer. } \\
\text { Destaca a gestão dos recursos } \\
\text { humanos, com o intuito de capa- } \\
\text { citar e motivar para que sejam } \\
\text { atingidos os objetivos propostos. } \\
\text { Base para desenvolvimento de } \\
\text { objetivos das demais perspectivas. }\end{array}$ & $\begin{array}{l}\text { Nível de satisfação de } \\
\text { funcionários } \\
\text { Rotatividade de } \\
\text { funcionários } \\
\text { Lucratividade por } \\
\text { funcionário } \\
\text { Capacitação e treina- } \\
\text { mento de funcionários } \\
\text { Participação de } \\
\text { funcionários }\end{array}$ & $\begin{array}{l}\text { Clientes } \\
\text { Financeira } \\
\text { Processos Internos }\end{array}$ \\
\hline
\end{tabular}


Quadro 2: Comparação entre setor privado e setor público nas perspectivas "financeira" e "clientes"

\begin{tabular}{|c|c|c|}
\hline Perspectiva & Privado & Público \\
\hline Financeira & $\begin{array}{l}\text { 1. As medidas financeiras são vistas como orien- } \\
\text { tações de curto prazo voltadas para retorno do } \\
\text { capital empregado (Roce), lucros por ação. } \\
\text { 2. O melhor desempenho financeiro tem } \\
\text { conexão direta com a gestão dos indicadores } \\
\text { de desempenho relacionados com a melhoria } \\
\text { das operações, o atendimento ao cliente e } \\
\text { novos produtos, com a busca por maiores } \\
\text { volumes de vendas e margens operacionais, } \\
\text { rapidez no giro do ativo e redução dos custos } \\
\text { operacionais. } \\
\text { 3. O retorno financeiro é decorrente do serviço } \\
\text { prestado ao cliente. } \\
\text { 4. Deve conter metas principais e que sirvam de } \\
\text { referência para as demais perspectivas, ou seja, } \\
\text { devem ter objetivos estratégicos e medidas asso- } \\
\text { ciadas à consecução de um ou mais objetivos. } \\
\text { 5. Os vetores de desempenho são condicio- } \\
\text { nados pelo setor de mercado e o ambiente } \\
\text { competitivo. } \\
\text { 6. Gera retorno para os investidores. } \\
\text { 7. Os gastos não são limitados aos valores or- } \\
\text { çados. }\end{array}$ & $\begin{array}{l}\text { 3. Não visa o retorno financeiro. } \\
\text { 4. As metas principais, objetivos estratégi- } \\
\text { cos e medidas associadas à consecução de } \\
\text { um ou mais objetivos estão relacionados } \\
\text { diretamente com o orçamento destinado a } \\
\text { cada órgão da APF. } \\
\text { 5. Não visa competitividade com o mer- } \\
\text { cado. } \\
\text { 6. Não gera retorno para os investi- } \\
\text { dores, mas deve prestar contas dos } \\
\text { custos e investimentos realizados. } \\
\text { 7. Os gastos são limitados aos valores } \\
\text { orçados. }\end{array}$ \\
\hline Clientes & $\begin{array}{l}\text { 1. As medidas voltadas para os clientes são } \\
\text { identificadas e concentradas para atender o } \\
\text { mercado que se deseja competir e, muitas vezes, } \\
\text { na personalização do cliente. } \\
\text { 2. Oferece produtos ou serviços alinhados } \\
\text { com a preferência dos clientes. } \\
\text { 3. Satisfaz o cliente de acordo com o interesse } \\
\text { da empresa. } \\
\text { 4. O desempenho financeiro é obtido por meio } \\
\text { de produtos e serviços valorizados pelos clientes. } \\
\text { 5. Ocorre a preferência de atuação em deter- } \\
\text { minada população e potenciais clientes. } \\
\text { 6. O mercado de clientes está de acordo com } \\
\text { suas preferências, dimensões de preços, quali- } \\
\text { dade, funcionalidade, imagem, reputação, } \\
\text { relacionamento e serviço. } \\
\text { 7. Os fornecedores podem sugerir novas } \\
\text { formas de negócios. } \\
\text { 8. Ocorre a mensuração da intensidade com } \\
\text { que atrai ou conquista novos clientes ou } \\
\text { negócios. }\end{array}$ & $\begin{array}{l}\text { 1. O público-alvo, que não é visto } \\
\text { como um cliente, pode ser dividido } \\
\text { em dois segmentos: } \\
\text { I - Administração Pública } \\
\text { Federal (APF): } \\
\text { Deve ser tratada de forma diferenciada, } \\
\text { pelo fato de receber orientações ou } \\
\text { determinações dos órgãos normativos e } \\
\text { de controle. } \\
\text { II - Cidadão/Sociedade: } \\
\text { A satisfação do cidadão/sociedade } \\
\text { é uma obrigação do Estado e os } \\
\text { interesses são direcionados para a } \\
\text { coletividade. }\end{array}$ \\
\hline
\end{tabular}


Segundo Kaplan e Norton (1997), o modelo pode ser facilmente adaptado para organizações públicas e instituições sem fins lucrativos. Perspectivas devem ser incorporadas ou eliminadas a um Balanced Scorecard, quando existe o interesse das partes interessadas e seja vital para o sucesso da estratégia idealizada.

Tendo como base as limitações descritas, as adaptações têm o objetivo de viabilizar a gestão estratégica nas organizações públicas, oferecendo base para servir ao cidadão/sociedade, mantendo os custos e investimentos sob o teto da previsão orçamentária e melhorando a articulação interna e externa com os diversos segmentos da sociedade, como empresas públicas ou privadas e organismos internacionais.

As adaptações são necessárias nas seguintes perspectivas: a financeira foi renomeada para orçamentária e a clientes, desmembrada em cidadão/sociedade e Administração Pública Federal. Além disso, foi criada a perspectiva de relações governamentais.

\section{Perspectivas adaptadas/agregadas ao BSC.Gov}

Perspectiva do cidadão/sociedade

Está relacionada com os objetivos estratégicos inerentes aos serviços a serem prestados ao cidadão e à sociedade, considerando os preceitos de uma gestão pública moderna focada em resultados e orientada para a transparência.

\section{Federal \\ Perspectiva da Administração Pública}

Envolve uma abordagem com foco na modernização da gestão pública, nos resultados das tomadas de decisões e no desenvolvimento da eficiência nas instituições públicas brasileiras.

\section{Perspectiva relações governamentais}

Envolve as articulações entre os órgãos de governo, empresas privadas e organismos internacionais, cujo objetivo principal é manter o relacionamento na busca de parcerias e soluções que sejam adequadas ao desenvolvimento das atividades e que venham a provocar interferências nos processos críticos de cada órgão da APF.

\section{Perspectiva orçamentária}

Envolve os custos operacionais e investimentos a serem realizados e que estejam previstos no orçamento público, sob a ótica dos recursos disponibilizados no plano plurianual (PPA), na Lei do Orçamento Público (LDO) e na Lei de Orçamento Anual (LOA), que, em conjunto, materializam o planejamento e a execução das políticas públicas federais.

Entre as seis perspectivas do BSC.Gov, a orçamentária é a mais crítica para os gestores públicos ao administrarem as organizações públicas brasileiras, pois nela são destinados os recursos financeiros que servem como base ao desenvolvimento dos objetivos estratégicos das demais perspectivas (Figura 5).

A perspectiva do aprendizado e crescimento, juntamente com a de processos internos, consomem a maior parte dos recursos e são muito importantes para a sustentação da perspectiva de Administração Pública Federal e de cidadão/sociedade; considerando que a perspectiva de relações governamentais é essencial para que ocorra a articulação entre os demais órgãos públicos normativos e de controle. 


\section{Balanced Scorecard.Gov como modelo de gestão estratégica para as organizações públicas}

\section{Modelo BSC.Gov}

O modelo de gestão estratégica BSC.Gov, adaptado para as organizações públicas, mantém a relação entre seis perspectivas equilibradas (Figura 6), que devem refletir a estratégia e a visão.

A estratégia deve ser descrita por meio das perspectivas: orçamentária, aprendizado e crescimento, relações governamentais, processos internos, Administração Pública Federal e cidadão/ sociedade.

\section{Etapas do BSC.Gov}

O Balanced Scorecard, como modelo de gestão estratégica para as organizações públicas, deve trilhar os seguintes passos:

Primeiro: traduzir a estratégia em objetivos estratégicos.

Segundo: estabelecer metas para cada perspectiva.

Terceiro: articular e manter relações governamentais intra e entre os órgãos das diversas esferas de governo, empresas privadas e organismos internacionais, em busca de parceria e inovação tecnológica.

Quarto: destacar os processos mais críticos para obtenção de desempenho superior no atendimento ao cidadão/sociedade e APF.

Quinto: investir na reciclagem de servidores e colaboradores, na infraestrutura de tecnologia da informação e comunicação que produza inovações e melhorias significativas para os processos internos, para a APF e para o cidadão/sociedade.

Finalmente, as metas orçamentárias devem ser claramente estabelecidas para que sustentem a execução dos demais objetivos estratégicos que constituem as demais perspectivas.

\section{Perspectivas do BSC.Gov e indicadores}

Os administradores públicos precisam reconhecer os vetores do sucesso de longo prazo, cujos objetivos e medidas utilizadas no BSC.Gov não se limitam a um conjunto de desempenho orçamentário e não orçamentário, mas derivam de um processo hierárquico top down, norteado pela visão e estratégia traduzida em objetivos estratégicos e medidas tangíveis que viabilizem a tomada de decisões nos diversos níveis e órgãos da Administração Pública Federal. A base é um conjunto de indicadores (Quadro 3) que demonstrem de forma eficiente os resultados e as melhorias advindas da modernização do modelo de gestão.

\section{Análise do BSC para imple- mentação nas organizações públicas}

A utilização do Balanced Scorecard (BSC), como referência de modelo de gestão estratégica a ser utilizado nas organizações públicas, teve como requisito uma análise iniciada com a identificação do relacionamento existente entre as perspectivas. Esse relacionamento demonstrou que o BSC, da forma como foi concebido, é aplicado conforme o Quadro 2: a perspectiva financeira é o objetivo principal, colocando-se no topo da figura, seguida da perspectiva de clientes, ficando a de aprendizado e crescimento na base e a de processos internos, mantendo o elo entre as demais.

As limitações que foram encontradas, após a comparação entre a aplicação do BSC no setor público e no setor privado, ocorreram em duas perspectivas: financeira e clientes.

No setor privado, a perspectiva financeira é voltada para a obtenção de lucro e para a competitividade, diferentemente do 


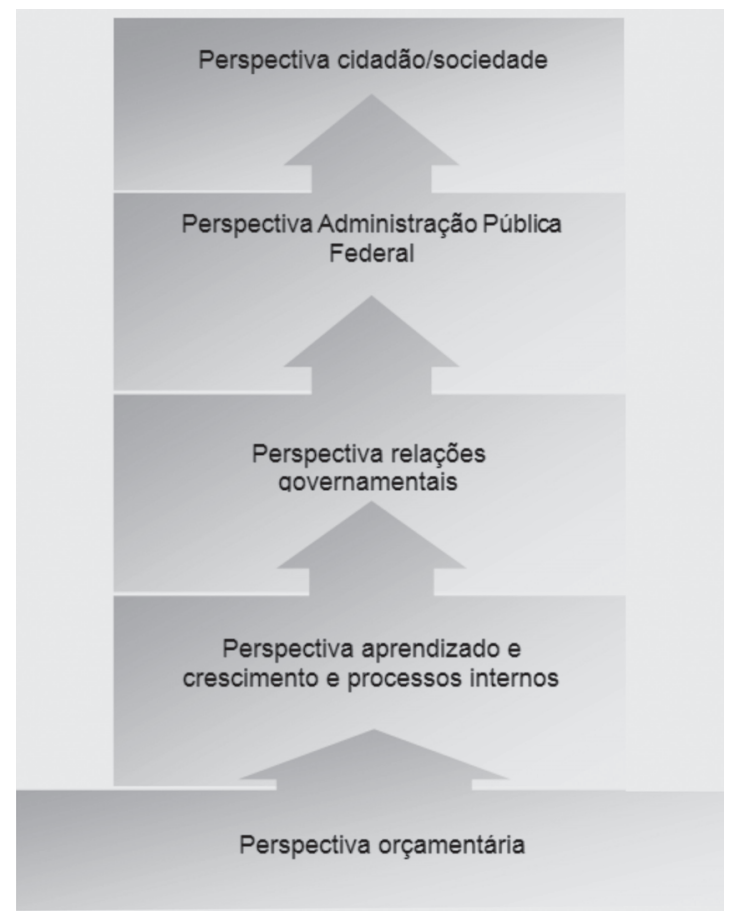

Fonte: Adaptado de Kaplan e Norton (1997) e de Averson (1999).

Figura 5: Relações de causa e efeito das perspectivas do Balanced Scorecard.Gov

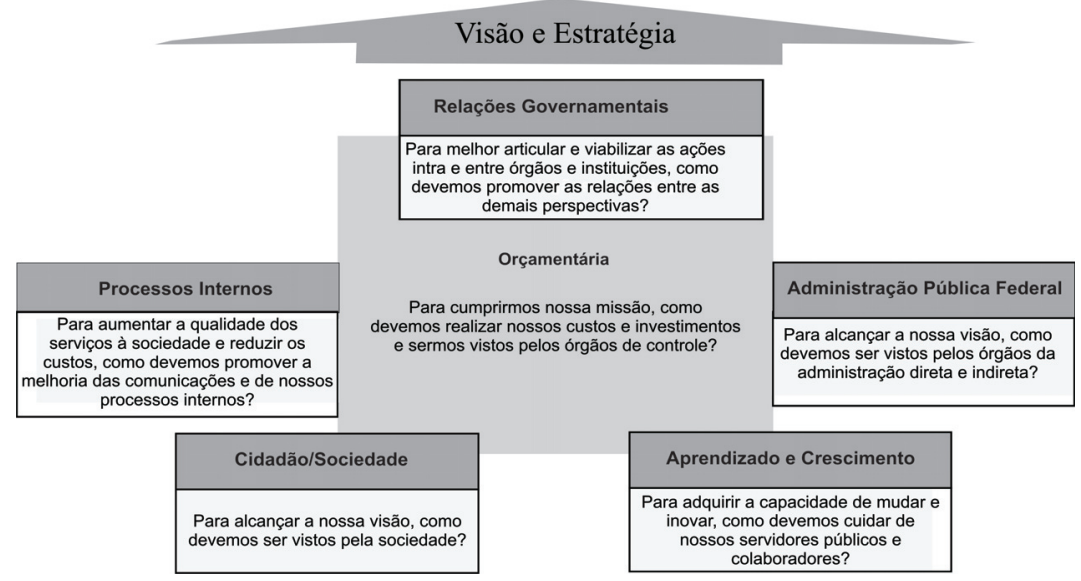

Fonte: Adaptado a partir de Robert S. Kaplan e David P. Norton (1997, p.10).

Figura 6: O Balanced Scorecard para as organizações públicas 
Quadro 3: Perspectivas BSC.Gov e indicadores

\begin{tabular}{|l|l|}
\hline Perspectivas & Indicadores \\
\hline Cidadão/Sociedade & $\begin{array}{l}\text { Serviços - Satisfação, confiança, preferência, tempo de } \\
\text { espera }\end{array}$ \\
\hline Administração Pública Federal & $\begin{array}{l}\text { Renovação interna - Número de projetos de pesquisa e } \\
\text { desenvolvimento } \\
\text { Desenvolvimento de tecnologia para os serviços } \\
\text { Práticas internas } \\
\text { Capacitação - Tecnologia adquirida } \\
\text { Práticas adotadas } \\
\text { Rede de relacionamentos - Parceria para pesquisa \& } \\
\text { desenvolvimento } \\
\text { Integração parceiros/fornecedores }\end{array}$ \\
\hline Relações governamentais & $\begin{array}{l}\text { Viabilidade tecnológica - Pesquisa e inovação } \\
\text { Rede de relacionamento } \\
\text { Grupos de trabalho - Práticas de trabalho compartilhadas } \\
\text { Retenção de técnicos } \\
\text { Grupos técnicos - Práticas de trabalho compartilhadas } \\
\text { Retenção de técnicos }\end{array}$ \\
\hline Orçamentária & $\begin{array}{l}\text { Custos - Gastos com aquisição e manutenção de ativos } \\
\text { Gastos com redução de produtos e serviços } \\
\text { Gastos com pesquisas e desenvolvimento de produtos e } \\
\text { melhoria de processos } \\
\text { Gastos com avaliação e certificações } \\
\text { Gastos com adequação às legislações } \\
\text { Gastos com acidentes } \\
\text { Redução de custos } \\
\text { Investimentos - Aquisição de recursos tecnológicos } \\
\text { Obras de engenharia }\end{array}$ \\
\hline a
\end{tabular}


setor público que não visa o lucro. Os recursos são destinados para atendimento à sociedade e ao cidadão, ou seja, para a coletividade, e sem qualquer tipo de competição. $\mathrm{Na}$ perspectiva de clientes, como é definida na iniciativa privada, os objetivos estratégicos e metas são diretamente relacionados para atender às necessidades de mercado e, muitas vezes, esse atendimento ocorre de forma personalizada. Tal personalização está de acordo com a preferência de atuação em determinada população e potenciais clientes, que visa obtenção e retenção de clientes. Esses fatos, tratados de forma tão simples e eficiente no setor privado, não são coerentes com as atividades desempenhadas pelos diversos segmentos do setor público, pois os "clientes", ou seja, a Administração Pública Federal e a sociedade/cidadão não têm essa conotação. A satisfação do cidadão/sociedade é uma obrigação do Estado brasileiro e os interesses são voltados para a coletividade. Tudo isso dificulta a implantação do BSC da forma como foi desenvolvido por Kaplan e Norton, requerendo, assim, adaptações e agregação de perspectivas.

Outro fator interessante é que as organizações públicas atuam de forma participativa com os demais órgãos, por meio de comitês, câmaras, conselhos que promovem reuniões com grupos de trabalho, definindo normas e padrões a serem utilizados, mas que não estão diretamente relacionados com os processos internos; no entanto, poderão causar impactos sobre esses mesmos processos. Assim sendo, o modelo não apresenta uma perspectiva que suporte os objetivos estratégicos e metas para as relações que existem intra e entre as organizações públicas.

As adaptações foram necessárias para que fosse possível a implementação nas organizações públicas, e ocorreram da seguinte forma: desmembramento da perspectiva de clientes em (Administração Pública Federal e cidadão/sociedade), adequação do nome da perspectiva "financeira" para "orçamentária" e a criação da perspectiva de "relações governamentais".

O principal objetivo de elaborar um modelo de gestão estratégica foi descrito com a proposta do Balanced Scorecard.Gov (BSC.Gov), que apresenta seis perspectivas: aprendizado e crescimento, relações governamentais, processos internos, Administração Pública Federal, cidadão/sociedade e a orçamentária, que está na base do modelo para suportar as demais perspectivas. Juntamente com esse modelo foram sugeridos indicadores para fins de padronização das métricas a serem utilizadas.

\section{Conclusão}

As organizações públicas, guiadas por uma diversidade de normas legais e pressionadas pela escassez orçamentária, estão atualmente colocadas perante a necessidade urgente de adaptar novos instrumentos de gestão pública, que possibilitem a melhoria de vida do cidadão/sociedade, da economia do país, e apresentem resultados de grande visibilidade e dimensão, que possam fazer do serviço público um serviço de qualidade, eficiente, transparente e compatível com os impostos cobrados.

As conclusões descritas mostram o resultado final a que se propôs o artigo. $\mathrm{O}$ intuito foi apresentar que, por meio das informações que podem ser obtidas pelo modelo proposto, é possível realizar a gestão estratégica nas organizações públicas, utilizando-se de um modelo concebido na iniciativa privada, como forma de auxiliar o gerenciamento das ações. Esse gerenciamento é mostrado nas 
perspectivas adaptadas e agregadas para esse fim, e, principalmente, na inversão da perspectiva orçamentária que serviu como base para as demais perspectivas do Balanced Scorecard.Gov.

Esse objetivo foi atingido com a análise inicial do modelo desenvolvido pelos professores Kaplan e Norton, passando pela identificação de suas limitações para implementação no setor público e adaptação de novo modelo para atendimento às organizações públicas.

O modelo de gestão estratégica, ora adaptado para as organizações públicas (BSC.Gov), é mais que uma ferramenta gerencial à disposição dos gestores públicos, no sentido de promover a redução das deficiências na prestação de serviço ao público. O BSC.Gov apresenta uma série de benefícios, como integração de medidas orçamentárias e não orçamentárias, vínculo da estratégia com o planejamento estratégico e orçamento (PPA, LOA, LDO), alinhamento organizacional, integração entre os órgãos públicos e maior proximidade no atendimento ao cidadão/sociedade, considerando que as ações do Estado devem estar orientadas ao cidadão/sociedade, na condição de usuários de serviços públicos e destinatários das ações das organizações públicas.

Destacam-se como fatores de maior contribuição do BSC.Gov a eficiência na busca da modernização da gestão pública e o controle orçamentário, visto que os objetivos estratégicos, relacionados com a perspectiva orçamentária, devem estar atrelados aos resultados que irão contribuir para a cultura e a busca da eficiência, privilegiando as organizações públicas que demonstrem maior capacidade de gerir os seus gastos.

(Artigo recebido em julho de 2010. Versão final em abril de 2011).

Nota

1 Campos (1998) o denomina de Cenário Balanceado.

\section{Referências bibliográficas}

AlmeIDA, Renilda Ouro de. BSC novos indicadores empresariais. Gazeta Mercantil. http:/ / www.perspectivas.com.br/bscga.htm. Acessado em: 18 de abril de 2011.

Averson, Paul (1999). The Balanced Scorecard and Knowledge Management. www.balancedscorecard.org/bscand/bsckm.html. Acessado em: 12 de abril de 2011.

Becker, Brian E.; Huselid, Mark A.; Ulrich, Dave. Gestão estratégica de pessoas com scorecard: interligando pessoas, estratégia e performance. Rio de Janeiro: Campus, 2001. Tradução de Afonso Celso da Cunha Serra.

Boesen, Thomas M. News tools for a new corporate culture: the budget-less revolution. Balanced Scorecard Report. Harvard Business School Publishing, v. 4, n. 1, jan.-fev. 2002. 
Campos, José Antônio. Cenário Balanceado. Balanced Scorecard. Painel de indicadores para a gestão estratégica dos negócios. São Paulo: Aquariana, 1998.

Certo, Samuel C.; Peter, J. Paul. Administração estratégica: planejamento e implantação da estratégia. São Paulo: Pearson Education do Brasil, 1993. p. 211-238.

Costa, Ana Paula Paulino da. Balanced Scorecard: Conceitos e guia de implementação. São Paulo: Atlas, 2006.

FILHO, Emílio Herrero. Balanced Scorecard e a Gestão Estratégica - Uma abordagem prática. Rio de Janeiro: Campus, 2005.

FresnedA, Paulo Sérgio Vilches. Estudo de Caso: modelo de gestão estratégica da Embrapa. In: Fórum Balanced Scorecard Brasil. Disponível em: http://www.symmetics. com.br. Acessado em: 15 de Abril de 2011.

Giuntini, Norberto; Rocha, Custódio T. M.; Pinto, Maurício G. C. A utilização do Balanced Scorecard como ferramenta de gestão estratégica. Disponível em: http:/ /www.sinescontabil. com.br/trabs_profissionais/contabilidade_e_os_avancos_tecnologicos/a_utilizacao_do_ balanced_scorecard_como_ferramenta_de_gestao_estrategica.htm. Acessado em: 20 de abril de 2011.

Grander, Charles. The hierarchy of objectives. Harvard Business Review, p. 63-74, maio/ jun. 1963.

Herzog, Ana Luiza. Pensar, planejar ... e fazer. Como o Unibanco está disseminando entre seus 28000 funcionários o balanced scorecard, sistema que promete tirar a estratégia da gaveta. Exame Fórum, Editora Abril, 787. ed., ano 37, n. 5, 12 de mar. de 2003. Henderson, Bruce D. As origens da estratégia. Estratégia: a busca da vantagem competitiva. Rio de Janeiro: Campus, 1998.

Justiça, Conselho Nacional. Metas prioritárias para 2010. Disponível em: http://www.cnj.jus.br/estrategia/index.php/definidas-as-metas-prioritarias-para-2010. Brasília, 2010. Consultado em: 19 de Abr. de 2011.

Kaplan, R.S. \& Norton, D.P. A estratégia em ação. Balanced Scorecard. Rio de Janeiro: Campus. 1997.

Kaplan, R.S. \& NorTON, D.P. Organização orientada para a estratégia. Como as empresas que adotam o Balanced Scorecard prosperam no novo ambiente de negócios. Rio de Janeiro: Campus, 2000.

Campus, 2000.

- Utilizando o balanced scorecard como sistema gerencial estratégico. Rio de Janeiro:

KAPLAN, Robert S. After september $11^{\text {th }}$ : the heightened role for cost and performance manegement. Balanced Scorecard Report. Harvard Business School Publishing. v. 4, n. 1, jan./fev. 2002.

Kaplan, R.S. \& NorTon, D.P. Mapas Estratégicos. Rio de Janeiro: Campus, 2004.

LEME, Rogério. Gestão de Desempenho Integrando Avaliação e Competências com o Balanced Scorecard. Rio de Janeiro: QualityMark, 2008.

Morris, Henry. The BSC and analytic application integration. Balanced Scorecard Report. Harvard Business School Publishing, v. 4, n. 1, jan.-fev. 2002.

Niven, Paul R. Balanced Scorecard passo a passo: elevando o desempenho. Rio de Janeiro: QualityMark Ed., 2008. 
OlIVEIRA, Djalma de P. Rebouças de. Excelência na administração estratégica: a competitividade para administrar o futuro das empresas: com depoimentos de executivos. São Paulo: Atlas, 1999.

Olve, Nils-Göran; Roy, Jan; WetTER, Magnus. Condutores da performance. Um guia prático para o uso do "Balanced Scorecard". Rio de Janeiro: Qualitymark Ed., 2001.

PorTER, Michael E. Vantagem competitiva: criando e sustentando um desempenho superior. Rio de Janeiro: Campus, 1989. Tradução de Elizabeth Maria de Pinho Braga

Porter, M. E. Competitive strategy. Nova York : Free Press, 1990.

Rezende, José Francisco. Balanced Scorecard e a Gestão do Capital Intelectual Alavancando a Performance Balanceada na Economia do Conhecimento. Rio de Janeiro: Campus, 2003.

SANTOS, Jairo Barreto dos. O balanced scorecard na integração dos sistemas de gestão. Disponível em: http://www.sqsqualidade.com.br/artigos_meio02.html. Acessado em: 12 de abr. 2011.

Santos, Neusa Maria Bastos F; Silva, José Alberto Teixeira da Silva; Santos, Roberto Fernandes dos. Criando valor com serviços compartilhados. São Paulo: Saraiva.

SILVA, Renato. Balanced Scorecard - BSC - Gestão do Ensino Superior. Curitiba: Juruá, 2009.

Tiffany, Paul; Peterson, Steven D. Planejamento estratégico: o melhor roteiro para um planejamento estratégico eficaz. Rio de Janeiro: Campus, 1998. Tradução de Ana Beatriz Rodrigues, Priscilla Martins Celeste. 


\section{Resumo-Resumen - Abstract}

\section{Balanced Scorecard: adequação para a gestão estratégica nas organizações públicas} Rozelito Felix, Patrícia do Prado Felix e Rafael Timóteo

Os órgãos da Administração Pública Federal (APF) terão maior êxito no alcance de seus objetivos estratégicos, investindo na implantação de um modelo de gestão estratégica, adaptado para o ambiente de governo, mantendo o alinhamento estratégico com os órgãos normativos e de controle.

Este artigo tem como objetivo apresentar um modelo de gestão estratégica, adaptado a partir das perspectivas do Balanced Scorecard (BSC) desenvolvido pelos professores da Harvard Business School, Robert Kaplan e David Norton, em 1992, para ser utilizado pelos órgãos da APF; tal modelo mantém um alinhamento estratégico organizacional com as recomendações do Tribunal de Contas da União (TCU).

O modelo irá permitir a gestão estratégica a partir da identificação dos objetivos estratégicos, metas, indicadores e ações referentes às perspectivas do Balanced Scorecard, o que permitirá o equilíbrio entre os indicadores de eficiência no acompanhamento das metas de cada órgão da APF, colaborando para uma gestão estratégica integrada, que venha a modernizar a gestão pública, agilizando as tomadas de decisões e a troca de informações.

Neste contexto, o artigo faz uma análise no BSC, verificando as relações de interdependência entre as perspectivas, detectando as limitações para sua implementação no setor público, adaptando e agregando novas perspectivas e finalmente elaborando um modelo de gestão estratégica, denominado como Balanced Scorecard.Gov (BSC.Gov).

Palavras-chave: Balanced Scorecard; alinhamento estratégico; Administração Pública Federal; gestão estratégica.

\section{Balanced Scorecard: adecuación para la gestión estratégica en las organizaciones públicas}

\section{Rozelito Felix, Patrícia do Prado Felix y Rafael Timóteo}

Los órganos de la Administración Pública Federal (APF) tendrá mayor éxito en el logro de sus objetivos estratégicos mediante la inversión en la aplicación de un modelo de gestión estratégica, adaptada al entorno de gobierno, manteniendo la alineación estratégica con los organismos reguladores y de control.

Este artículo tiene como objetivo presentar un modelo de gestión estratégica, una adaptación de las perspectivas del Balanced Scorecard (BSC) desarrollado por los profesores de Harvard Business School, Robert Kaplan y David Norton en 1992, para ser utilizado por los órganos de la APF, este modelo mantiene una alineación organizativa estratégica con las recomendaciones del Tribunal de Cuentas (TCU).

El modelo permitirá la gestión estratégica de la identificación de objetivos estratégicos, metas y acciones relacionadas con las perspectivas del Balanced Scorecard, lo que promoverá un equilibrio entre los indicadores de resultados en el seguimiento de los objetivos de cada organismo de la APF, que contribuyen a una gestión estratégica integrada, que conduzca a la modernización de la administración pública, a la racionalización de la toma de decisiones y el intercambio de información.

En este contexto, este artículo analiza el BSC, la verificación de la interdependencia entre las perspectivas, la identificación de las limitaciones para su aplicación en el sector público la adaptación, y la adición de nuevas perspectivas y, finalmente, el desarrollo de un modelo de gestión estratégica, conocido como equilibrado Scorecard.Gov (BSC.Gov).

Palabras clave: Balanced Scorecard, la alineación estratégica, la Administración Pública Federal, la gestión estratégica. 
Balanced Scorecard: adequacy to the strategic management on public organizations. Rozelito Felix, Patricia do Prado Felix and Rafael Timóteo

The FPA bodies will be more successful achieving their strategic goals by investing on the deployment of a strategic management model, adapted to the government location, keeping the strategic alignment with control regulatory agencies.

This article aims to present a strategic management model, adapted from the perspectives of the Balanced Scorecard - BSC developed by the Harvard Business School professors, Robert Kaplan and David Norton in 1992, to be use by agencies of the Federal Public Administration - FPA as a factor in strategic organizational alignment according to Union Accounts Court-TCU.

The model will allow a balance between the performance indicators in monitoring the mark of FPA bodies, collaborating in an integrated strategic management, which will modernize the public administration, speeding up the decisions and information exchange.

In this context, this article analyzes the BSC, verifying the interdependency between the perspectives, detecting the constraints to the implementation in the public area, adding and adapting new perspectives and finally making a strategic management model, known by Balanced Scorecard.Gov (BSC.Gov).

Keywords: Balanced Scorecard, strategic alignment, the federal public administration, strategic management..

Rozelito Felix da Silva

Possui MBA em Estratégia da Informação pela Fundação Getúlio Vargas (FGV) e mestrado em Engenharia Elétrica pela UnB. Atua no Departamento de Segurança da Informação e Comunicações da Presidência da República. Contato: rfelixs@brturbo.com.br

Patrícia do Prado Felix

Pós-graduada em Análise de Sistemas pela Universidade do Estado da Bahia (UNEB) e em Segurança da Informação pelo Instituto de Educação Superior de Brasília (IESB). Mestre em Engenharia da Produção pela Universidade Federal de Santa Catarina (UFSC). Trabalha com o banco de dados do Sistema Único de Saúde (DATASUS/ Ministério da Saúde). Contato: patfelix@brturbo.com.br

Rafael Timóteo

Mestre em Telemática e Sistemas de Informação e pós-doutorado pela École Supérieure d’Electricité (Supelec). Doutor em Processamento de Sinais e Telecomunicações pela Université de Rennes 1-França. Atua no departamento de Engenharia Elétrica da UnB. Contato: desousa@unb.br 